\title{
Spatio-temporal evolution of the West African monsoon during the last deglaciation
}

\author{
Syee Weldeab, ${ }^{1}$ Martin Frank, ${ }^{2}$ Torben Stichel, ${ }^{2}$ Brian Haley, ${ }^{3}$ and Mark Sangen ${ }^{4}$ \\ Received 14 April 2011; revised 16 May 2011; accepted 18 May 2011; published 6 July 2011.
}

[1] On the basis of a multi-proxy data set from the Gulf of Guinea (eastern equatorial Atlantic) we reconstruct the spatiotemporal evolution of the West African monsoon (WAM) and present evidence for a decoupling between latitudinal shifts of the rain belt and WAM intensification. The onset of deglacial monsoon invigoration at $\sim 16,600$ years before present lagged northward migration of a weak rainfall zone by $\sim 2800$ years. Conversely, during the Younger Dryas (YD) time interval, WAM precipitation was severely reduced but we find no evidence for a large-scale retreat of the rainfall front. This observation is not in agreement with the hypothesis of a large-scale shift of the intertropical convergence zone south of the tropical WAM region during the YD. Our results can be better reconciled with the newly emerging concept of a strong influence of Tropical Easterly and African Easterly Jets on modern WAM. Citation: Weldeab, S., M. Frank, T. Stichel, B. Haley, and M. Sangen (2011), Spatio-temporal evolution of the West African monsoon during the last deglaciation, Geophys. Res. Lett., 38, L13703, doi:10.1029/2011GL047805.

\section{Introduction}

[2] Deglacial and glacial millennial-scale climate oscillations in northern high latitudes [North Greenland Ice Core Project Members, 2004] significantly influenced West African monsoon precipitation [Adegbie et al., 2003; Lézine and Cazet, 2005; Sangen, 2011; Weldeab et al., 2007a, 2007b, 2005]. The physical mechanism that tightly linked rapid drops in WAM precipitation to the cold spells of northern high latitudes is, however, poorly understood. A lack of sufficiently resolved records along a latitudinal transect across the WAM core area together with age model uncertainties inherent in comparisons of records from different locations [Collins et al., 2011] have so far presented an obstacle to test the hypothesis of a large-scale ITCZ displacement as the main cause of the centennial-to-millennial scale WAM rainfall declines [Chang et al., 2008]. In this study we circumvent the above limitations by focusing on a single high-resolution climate archive and analyze proxies that independently allow insights into both large-scale latitudinal rain belt migration and changes in the rainfall intensity over the WAM core area.

\footnotetext{
${ }^{1}$ Department of Earth Science, University of California, Santa Barbara, California, USA.

${ }^{2}$ Leibniz-Institut für Meereswissenschaften an der Universität Kiel (IFM-GEOMAR), Kiel, Germany.

${ }^{3}$ College of Oceanic and Atmospheric Sciences, Oregon State University, Corvallis, Oregon, USA.

${ }^{4}$ Physische Geographie, Goethe Universität Frankfurt am Main, Frankfurt, Germany.
}

Copyright 2011 by the American Geophysical Union. 0094-8276/11/2011GL047805
[3] We generated a multi-proxy record from marine sediment core MD03-2707 $\left(02^{\circ} 30.11^{\prime} \mathrm{N}, 09^{\circ} 23.68^{\prime} \mathrm{E}, 1295 \mathrm{~m}\right)$, which was recovered in the eastern Gulf of Guinea, eastern equatorial Atlantic (EEA) (Figure 1). The excellent quality of this sediment core for research on past WAM has been demonstrated in previous studies [Weldeab et al., 2007a, 2007b], in which the age model and oceanographic setting have been described. The core site is located adjacent to major river outflows, resulting in high accumulation rates of terrigenous sediments (Figure 1). The river drainage basins cover large parts of WAM area and the sediment loads of each river have a distinct radiogenic isotope signature (Figure 2a), reflecting the geology of the catchments. Temporal changes of the terrigenous sediment composition of core MD03-2707 are thus expected to provide valuable insights into the spatio-temporal evolution of the WAM system.

\section{Method}

[4] We analyzed the radiogenic ${ }^{143} \mathrm{Nd} /{ }^{144} \mathrm{Nd}$ and ${ }^{87} \mathrm{Sr} /{ }^{86} \mathrm{Sr}$ isotope composition of major river sediments and the terrigenous fraction $(\leq 63 \mu \mathrm{m})$ of marine sediment core MD032707 after removal of the biogenic components and the early diagenetic ferromanganese coatings. ${ }^{143} \mathrm{Nd} /{ }^{144} \mathrm{Nd}$ data were determined using a TRITON 1 thermal ionization mass spectrometer at IFM-GEOMAR. The external reproducibility was between \pm 0.2 and $\pm 0.35 \varepsilon \mathrm{Nd}(2 \sigma)$. The $\mathrm{Sr}$-isotopic composition was measured on a Nu Plasma HR MC-ICPMS at IFM-GEOMAR. The external reproducibility was $24 \mathrm{ppm}$ $(2 \sigma)$. A detailed description of the sample preparation and analytical approaches is provided in the auxiliary material. ${ }^{1}$ In this study we use the $\varepsilon \mathrm{Nd}$ notation for $\mathrm{Nd}$ isotope ratios, which is the present day ${ }^{143} \mathrm{Nd} /{ }^{144} \mathrm{Nd}$ expressed as deviations from the composition of the chondritic uniform reservoir (CHUR): $\varepsilon \mathrm{Nd}=\left[\left({ }^{143} \mathrm{Nd} /{ }^{144} \mathrm{Nd}\right)_{\text {sample }} /\left({ }^{143} \mathrm{Nd} /{ }^{144} \mathrm{Nd}\right)_{\mathrm{CHUR}}\right)$ $-1]^{*} 10^{4}$, with present-day CHUR being equal to 0.512638 [Jacobsen and Wasserburg, 1980].

\section{Result and Discussion}

[5] The Ntem River drains the southernmost periphery of the modern summer WAM area that consists of Archean and Early Proterozoic formations (Ntem complex) [Toteu et al., 2001] whose weathering products have characteristically negative $\varepsilon N d$ values (Figures 1 and $2 a$ ). The Sanaga and Nyong basins cover a catchment area of $163,000 \mathrm{~km}^{2}$ and predominately consists of Meso- to Neoproterozoic Pan-African granitoids, the Yaoundé Group (gneisses), and paleoproterozoic gneisses [Toteu et al., 2001]. Nd isotope

\footnotetext{
${ }^{1}$ Auxiliary materials are available in the HTML. doi:10.1029/
} 2011GL047805. 


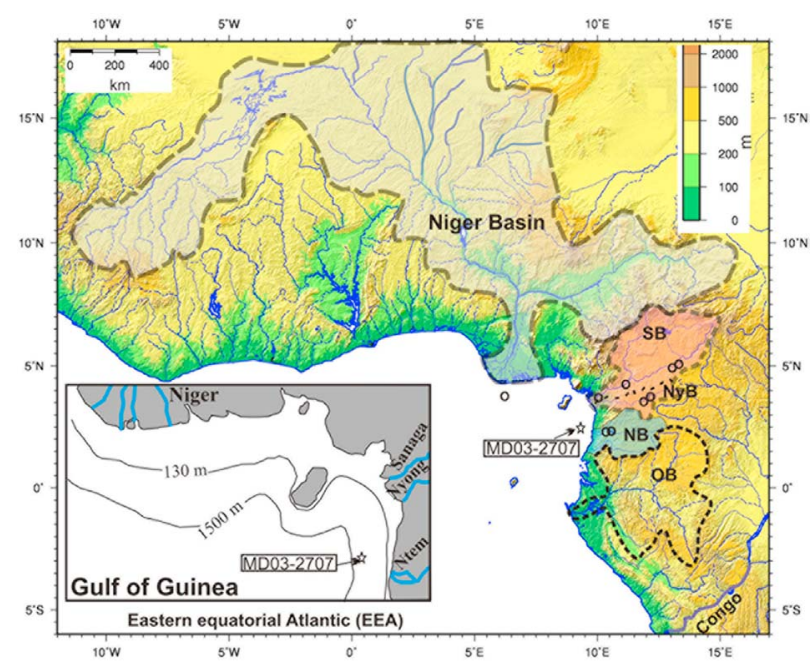

Figure 1. Topographic map of West Africa showing the Niger Basin, Sanaga Basin (SB), Nyong Basin (NyB), and Ntem Basin (NB), and Oogue (OB). Triangles along and off the rivers indicate sampling sites of river sediment and core top (off Niger) used for Nd and Sr isotope characterization of the river basins. The inset shows core location and bathymetry of Gulf of Guinea.

signatures of the Sanaga and Nyong basins are clearly distinguishable from those of the Ntem basin by their significantly positive $\varepsilon N d$ values (Figure $2 a$ ). Similarly positive $\varepsilon \mathrm{Nd}$ values were also obtained from suspended matter of the Niger river and from core top sediments adjacent to the Niger river mouth (Figures 1 and 2a). A geological map of the riverine basins that puts the $\mathrm{Nd}$ isotope variation into the lithological context of exposed rock units is provided in the auxiliary material. The average $\varepsilon \mathrm{Nd}$ value of sediments from each of these rivers constitutes an end-member $\mathrm{Nd}$ isotope composition for the mixture of the terrigenous sediments deposited at the location of core MD03-2707 (Figure 2a).

[6] For the down core record, we will mainly focus on the ${ }^{143} \mathrm{Nd} /{ }^{144} \mathrm{Nd}$ data because the ${ }^{87} \mathrm{Sr} /{ }^{86} \mathrm{Sr}$ signatures of the main sources are less distinctive (Figures $2 \mathrm{a}$ and $3 \mathrm{c}$ ). Terrigenous sediment with the most negative $\varepsilon \mathrm{Nd}$ values was deposited during the period between 19,800 and 20,300 years before present (BP). It is obvious that Saharan/Sahelian dust with relatively positive $\varepsilon \mathrm{Nd}$ signature (Figure $2 \mathrm{a}$ ) and an estimated glacial mass accumulation rate of $\sim 0.8 \mathrm{~g} / \mathrm{cm}^{2} / \mathrm{kyr}$ in the equatorial Atlantic [Rea, 1994] played an insignificant role for $\mathrm{Nd}$ isotope composition of core MD03-2707 and EEA sediment accumulation rate, which amounted to $28 \pm$ $2.8 \mathrm{~g} / \mathrm{cm}^{2} / \mathrm{kyr}(\mathrm{n}=5)$ between 18,800 and 20,200 years BP (Figure $2 b$ ). The glacial $\varepsilon \mathrm{Nd}$ values suggest a dominance of riverine sediments from the Ntem basin (Figure 2a). A simplified mass balance calculation (see auxiliary material) suggests that during the glacial $87 \%$ of the terrigenous sediment originated from the Ntem catchment. Dry climate over the Sanaga-Nyong catchment and sea level low stand of $130 \pm 5 \mathrm{~m}$ in the Gulf of Guinea during the Last Glacial Maximum [Giresse et al., 1995] most likely contributed to the high proportion of Ntem sediments by shortening the distance between the core site and the Ntem river outflow.

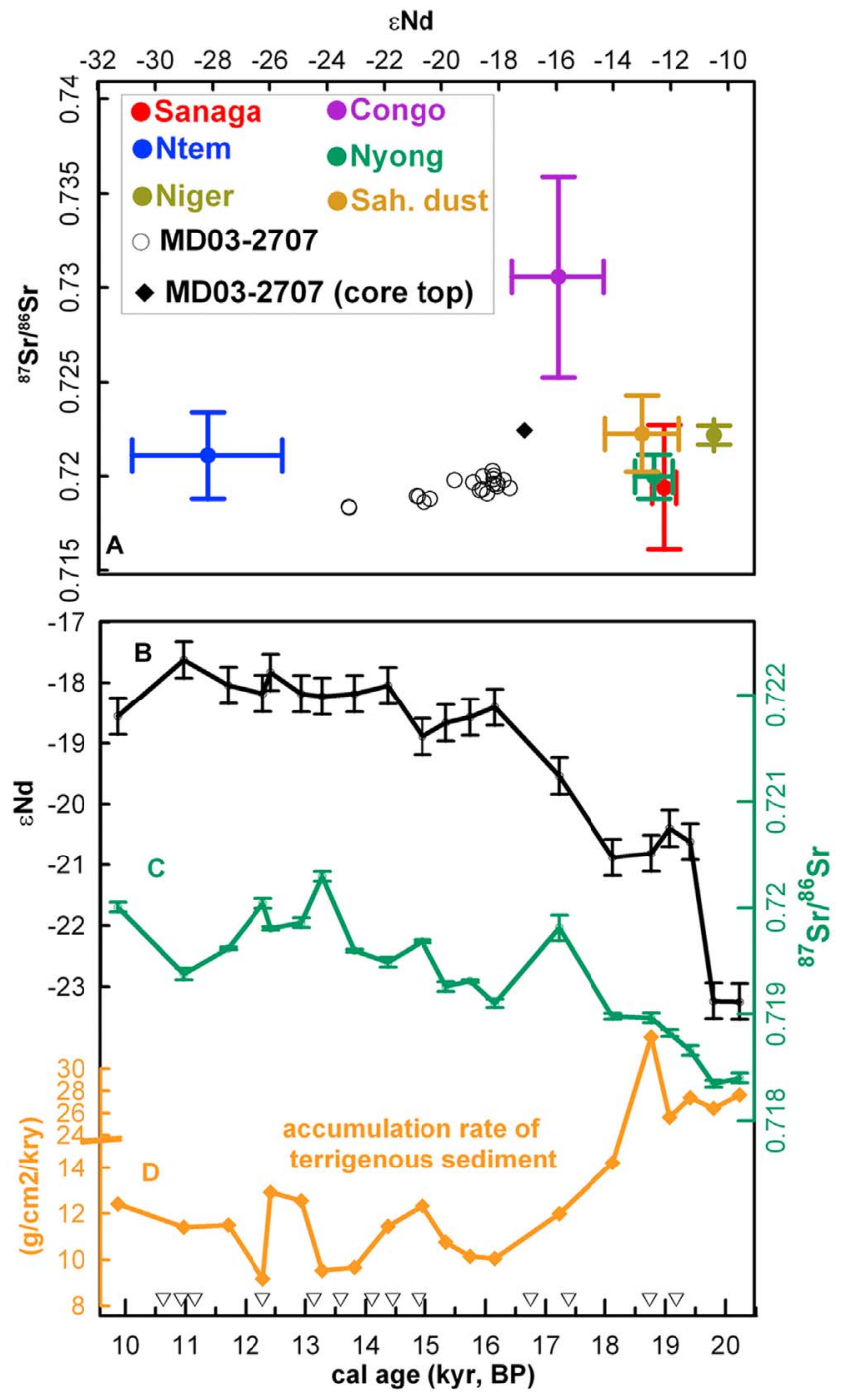

Figure 2. (a) Average ${ }^{87} \mathrm{Sr} /{ }^{86} \mathrm{Sr}$ and $\varepsilon \mathrm{Nd}$ signatures analyzed in river sediments from Ntem, Sanaga, Nyong, and Niger. The $\varepsilon \mathrm{Nd}$ value of Niger suspended sediment is from Goldstein et al. [1984] plotted versus ${ }^{87} \mathrm{Sr} /{ }^{86} \mathrm{Sr}$ analyzed in the terrigenous fraction of core-top sediment recovered from near the outflow of the Niger River (MD03-2706: $3^{\circ} 37^{\prime} \mathrm{N} / 5^{\circ} 29^{\prime} \mathrm{E}$ ). ${ }^{87} \mathrm{Sr} /{ }^{86} \mathrm{Sr}$ and $\varepsilon \mathrm{Nd}$ data of suspended sediment from Congo river and central Saharan/Sahelian dust are from Allègre et al. [1996] and Grousset and Biscaye [2005], respectively. Bars indicate standard deviations from average values of several measurements from each river catchment (see Figure 1). Black circles and filled diamond show ${ }^{87} \mathrm{Sr} /{ }^{86} \mathrm{Sr}$ and $\varepsilon \mathrm{Nd}$ values of the terrigenous fraction $(63 \mu \mathrm{m})$ in down and core of MD03-2707, respectively. (b and c) Down core ${ }^{87} \mathrm{Sr} /{ }^{86} \mathrm{Sr}$ and $\varepsilon \mathrm{Nd}$ values versus the age model of MD03-2707. Vertical bars denote the external reproducibility $(2 \sigma)$ of repeated standard measurements of $\varepsilon \mathrm{Nd}$ and reproducibility of repeated sample measurements (Figure 2c). (d) Accumulation rates of the terrigenous fraction of down core samples. Triangles along the age axis indicate age model control points based on ${ }^{14} \mathrm{C}$-datings of Globigerinoides ruber (pink variety) [Weldeab et al., 2007a]. All ${ }^{87} \mathrm{Sr} /{ }^{86} \mathrm{Sr}$ and $\varepsilon \mathrm{Nd}$ data listed in the auxiliary material. 


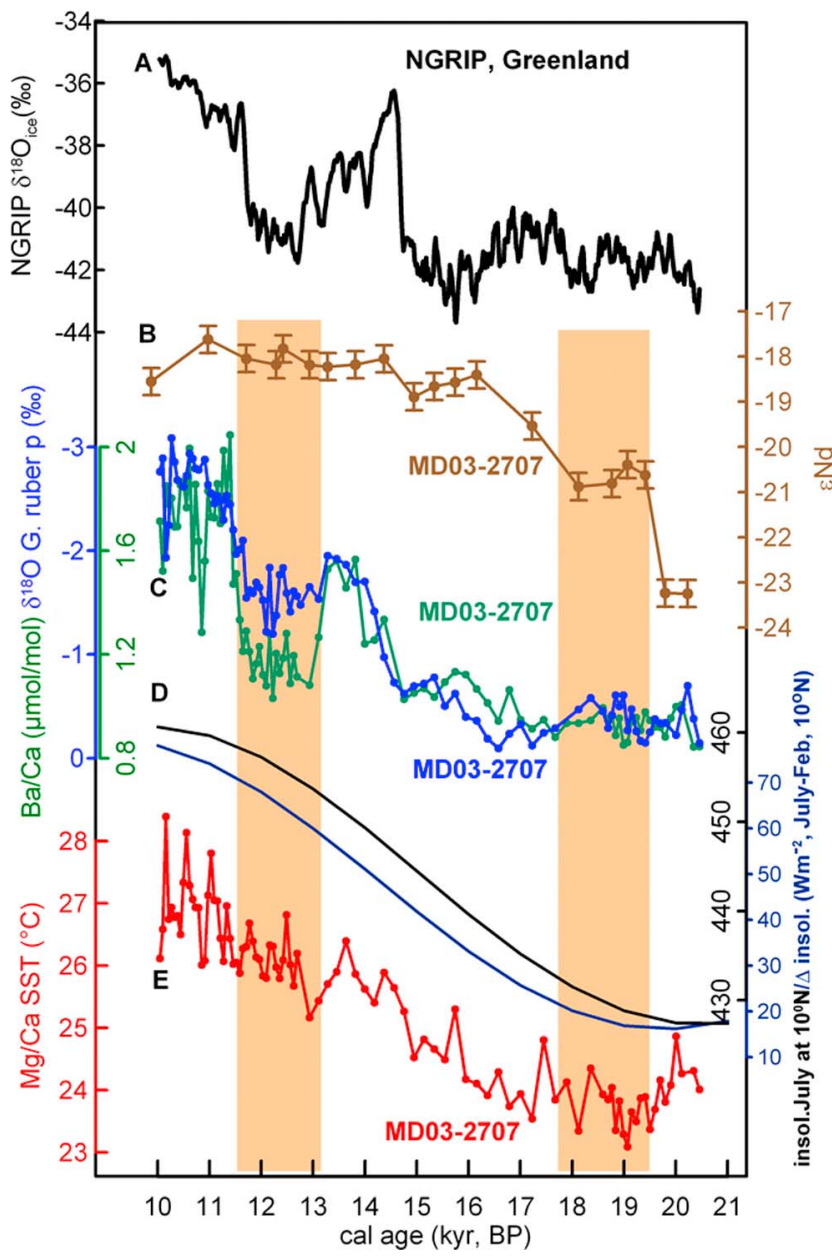

Figure 3. Comparison of spatio-temporal evolution of the WAM precipitation and SST in the EEA with high northern latitude climate (a) as recorded in the NGRIP ice core [North Greenland Ice Core Project Members, 2004]. (b) As in Figure 2b. (c) Planktic foraminiferal (G. ruber pink) $\mathrm{Ba} / \mathrm{Ca}$ (green line) and $\delta^{18} \mathrm{O}$ (blue line) analyzed in MD2707 core materials and used as proxies for riverine discharge [Weldeab et al., 2007a]. (d) Solar insolation (black curve) and seasonal contrast in solar insolation (blue curve: July 21 minus February 15th insolation values) [Berger and Loutre, 1991]. (e) $\mathrm{Mg} / \mathrm{Ca}$-based SST estimate reconstructed using MD2707 core materials [Weldeab et al., 2007a]. Orange bars indicate time intervals of decoupled changes in monsoon intensity, as indicated by high $\mathrm{Ba} / \mathrm{Ca}$ and low $\delta^{18} \mathrm{O}$ values, and areal extent of the monsoon precipitation.

At $\sim 19,400$ years BP we note a rapid shift towards more positive $\varepsilon \mathrm{Nd}$ values that persisted at $\varepsilon \mathrm{Nd}$ values of $-20.7 \pm$ $0.2(n=4)$ until 18,100 years BP. Significant input of suspended sediment from the Congo River is unlikely, as this would have caused significant changes in the ${ }^{87} \mathrm{Sr} /{ }^{86} \mathrm{Sr}$ ratio of MD03-2707, which we do not observe (Figure 2a). On the basis of its $\mathrm{Nd}$ isotope signature and the proximity of the river mouths to the site of MD03-2707, as well as persistently high accumulation rates, riverine sediment from the Sanaga and Nyong basins was the most likely source for this rapid shift in the $\varepsilon \mathrm{Nd}$ signature. Compilation of several sea-level reconstructions [Hanebuth et al., 2009] indicates a global sea-level rise of at maximum $20 \mathrm{~m}$ between 19,400 and 18,000 years BP. Pollen record from Lake Barombi Mbo (west of the Sanaga basin) suggests significant climate amelioration beginning at $\sim 20,00$ years BP [Maley and Brenac, 1998]. Relatively increased influence of sediment from Sanaga and Nyong basins at the core site was most likely facilitated by an increase in sea level (decreasing the influence of Ntem basin to $\sim 70 \%$ ) and a northward displacement of the rainfall zone. Starting at $\sim 18,100$ years BP, a second shift of the $\varepsilon \mathrm{Nd}$ values towards more positive signatures occurred, which was accompanied by a gradual decline of the accumulation rate. According to our mass balance calculation, the $\varepsilon \mathrm{Nd}$ trend peaking at $\sim 16,200$ years BP reflects a $40-45 \%$ contribution of terrigenous sediment from Sanag and Nyong basins. Thus we argue that the rainfall front crossed a significant portion of the Sanaga and Niger basins between $\sim 16,200$ and 15,000 years BP. The first post-glacial lake level rise in Lake Bosumtwi $\left(6^{\circ} 30^{\prime} \mathrm{N}\right)$ at $\sim 16,300$ years BP [Shanahan et al., 2006] and a notable climate amelioration in the Niger basin at $\sim 16,000$ [Lézine and Cazet, 2005] lends strong support to our interpretation. The last change towards more positive $\varepsilon \mathrm{Nd}$ signatures occurred at approximately $\sim 14,600$ years BP and coincided, within dating uncertainties, with the onset of the Bølling-Allerød time interval. This final shift and subsequent plateau value of $\varepsilon \mathrm{Nd}=-18.1 \pm 0.3$ $(n=9)$ throughout the late deglaciation and early Holocene indicates that the rain belt finally reached and traversed the northern boundary of the Sanaga basin at $\sim 14,600$ years BP. This is fully in accord with the onset of increased sediment deposition off the Senegal river [Mulitza et al., 2008] at $\sim 14,600$ years BP, the catchment of which is located to the northwest of the Niger basin.

[7] The sequence of shifts in the $\mathrm{Nd}$ isotope composition over the last deglaciation uniquely recorded the pace of the WAM spatio-temporal evolution. Present day seasonal data show that the northernmost rainfall front of the summer WAM closely follows the position of the intertropical convergence zone (ITCZ) [Nicholson, 2009]. On the basis of the assumption that this relationship also existed throughout the last deglaciation, we propose that the continuously increasing influence of riverine sediments from the central and northern river basin indicates a gradual northward shift of the rainfall area and the mean summer position of the ITCZ. It is important to note that the main shift in riverine sediment source, as suggested by the $\varepsilon \mathrm{Nd}$ record, does not provide information about the intensity of WAM rainfall. However, the magnitude of sea surface freshening above the MD03-2707 site, as recorded using two independent proxies [Weldeab et al., 2007b] (Figure 3c), provides a direct measure for changes in the amount of riverine freshwater input, reflecting variation of the WAM intensity.

[8] In previous studies [Weldeab et al., 2007a, 2007b] $\mathrm{Ba} / \mathrm{Ca}$ and $\delta^{18} \mathrm{O}$ in calcite tests of surface-dwelling planktonic foraminifer, Globigerinoides ruber pink, have been introduced as indicators for changes in runoff, reflecting precipitation changes in the riverine basins (Figure 3c). Comparison between the timing of rain belt migration, as suggested by the $\varepsilon \mathrm{Nd}$, and changes in the amount of riverine fresh water entering the Gulf of Guinea (Figures 3b and 3c) reveals two prominent features. Firstly, a slight increase in freshwater input, most likely reflecting incipient WAM rainfall intensification, was recorded at $\sim 16,600$ years BP 
and lagged the onset of northward movement of rainfall front from its glacial position by $\sim 2,800$ years. Weak seasonal contrasts in solar insolation over the Sanaga-Nyong basin (Figure 3e) may have been crucial in suppressing notable intensification of summer monsoon precipitation during the early deglacial phase (Figure 3 ). Secondly, during the YD time interval (11,600-12,900 years BP) [North Greenland Ice Core Project Members, 2004] the hydrological proxy records indicate a sharp drop in the WAM precipitation (Figure 3c). Pollen-data from the Niger basin [Lézine and Cazet, 2005] and a lake close to Sanaga basins [Maley and Brenac, 1998] show that the weak WAM precipitation during the YD, as indicated by our spatially integrated data (Figure 3c), equally affected the entire WAM core area. The $\mathrm{Nd}$ isotope record, however, shows no significant changes compared to the time intervals prior to and after the YD, indicating that there were no large-scale changes in the amount and sources of riverine sediment supply. The supply of terrigenous sediment over the core site is mainly controlled by the amount of riverine sediment loads, the pathway of sediment transport, and the proximity of river mouths to the core site, which may have been affected by sea-level changes during the deglaciation. Recent sea-level reconstruction suggests, however, no dramatic shift during the YD [Bard et al., 2010] as compared to time interval prior and after the YD. Alternatively, simultaneous changes of sediment contributions from the three main source areas may have resulted in the stable $\varepsilon \mathrm{Nd}$ signature over the YD period. However, a mixing calculation shows that maintaining the $\mathrm{Nd}$ isotope composition at its YD values while at the same time significantly decreasing sediment supply from the Niger and Sanaga-Nyong basins would have to be balanced by an unrealistically large decrease of sediment input from the Ntem basin (auxiliary material). A large-scale change in terrigenous sediment input is also not supported by the trend of the sediment accumulation rate (Figure 2d).

[9] To put the YD $\varepsilon \mathrm{Nd}$ record into context with other Gulf of Guinea proxy records, a brief summary of the latter is provided. Deglacial SST estimates in the EEA (Figure 3e) indicate continuous warming without any imprint of the YD northern hemisphere cooling. In line with the EEA SST reconstruction, terrestrial temperature reconstructions over the Sanaga basin [Maley and Brenac, 1998] and Congo basin (latitudinally extending up to $6^{\circ} \mathrm{N}$ ) [Weijers et al., 2007] suggest a continuous rise of continental air temperatures that persisted throughout the YD period. Consistent with the WAM reconstruction from core MD2707, precipitation reconstruction in the coastal region of the Gulf of Guinea [Maley and Brenac, 1998; Shanahan et al., 2006] indicates severely reduced rainfall during the YD. All these proxy-based observations are not compatible with a reversal of the thermal gradient, a large-scale ITCZ retreat above the river basins, and precipitation increase over the Gulf of Guinea coastal region as hypothesized by Chang et al. [2008]. Instead, the scenario that emerges is that WAM precipitation during the $\mathrm{YD}$, although severely weakened (Figure 3c), covered a large latitudinal range extending from the Ntem basin to the northern boundary of the Sanaga basin.

[10] Invoking a direct atmospheric linkage between the sharp drop of WAM rainfall and the YD high latitude cold spell must be consistent with the seasonality of the involved processes. The WAM is a low latitude summer phenome- non, while there is evidence that the YD time interval in the northern high and mid latitude was characterized by anomalously cold winters and relatively mild summer temperatures [Atkinson et al., 1987; Denton et al., 2005]. If the suggested YD seasonality is realistic, the WAM-high latitude climate linkage was most likely established via winter pre-conditionings that influenced the strength of subsequent summer atmospheric features relevant for the WAM system [Barnett et al., 1988]. Modern observational data show that summer WAM precipitation consists of a relatively weak rainfall zone at northernmost boundary of the monsoon area, which is associated with the ITCZ position, and an intense rain belt that is linked to ascending air masses sandwiched between the African Easterly Jet (AEJ) and Tropical Easterly Jet (TEJ) [Nicholson, 2009]. Both AEJ and TEJ are located south of the ITCZ. Furthermore, modern data also show that during Sahel droughts the main rain belt retreated several hundred kilometers southwards, while the weak rainfall zone linked to the ITCZ remained over the northern Sahel [Nicholson, 2009]. Whether the modern observation provides a viable mechanism for the reconstructed spatial patterns of West African monsoon precipitation during the $\mathrm{YD}$, is subject to future modeling studies that take into account proxy-based observations. It becomes, however, clear that the spatial patterns of WAM precipitation and the thermal gradients generated in previous modeling study [Chang et al., 2008] are not compatible with the observational paleo-data from the tropical region of the WAM system.

[11] Our records for the first time provide a continuous measure for the pace of deglacial WAM evolution, providing hitherto unprecedented insights into the spatio-temporal evolution of the WAM system. On orbital time scales, a deglacial northward shift of the rain belt followed the pace of changes in solar insolation in accord with Kutzbach hypothesis [Kutzbach, 1981]. The evidence that during the YD a severely weakened WAM was not accompanied by large-scale shift of rainfall zone within the tropical WAM area emphasizes the importance of regional characteristics and atmospheric features of the WAM system on centennial to millennial time scales.

[12] Acknowledgments. We thank Jan Fietzke for technical support and Anton Eisenhauer and Folkmar Hauff for providing access to the TIMS lab. We also thank the two anonymous reviewers for their insightful comments that helped to improve a previous version of this paper. Weldeab acknowledges the generous start-up package from UCSB.

[13] The Editor thanks the two anonymous reviewers for their assistance in evaluating this paper.

\section{References}

Allègre, C. J., et al. (1996), Sr-Nd-Pb isotope systematics in Amazon and Congo River systems: Constraints about erosion processes, Chem. Geol. 131(1-4), 93-112, doi:10.1016/0009-2541(96)00028-9.

Atkinson, T. C., et al. (1987), Seasonal temperatures in Britain during the past 22,000 years, reconstructed using beetle remains, Nature, 325 (6105), 587-592, doi:10.1038/325587a0.

Bard, E., et al. (2010), Deglacial meltwater pulse 1B and Younger Dryas sea levels revisited with boreholes at Tahiti, Science, 327, 1235-1237, doi:10.1126/science.1180557.

Barnett, T. P., et al. (1988), The effect of Eurasian snow cover on global climate, Science, 239, 504-507, doi:10.1126/science.239.4839.504.

Berger, A., and M. F. Loutre (1991), Insolation values for the climate of the last 10 million years, Quat. Sci. Rev., 10, 297-317, doi:10.1016/02773791(91)90033-Q. 
Chang, P., et al. (2008), Oceanic link between abrupt changes in the North Atlantic Ocean and the African monsoon, Nat. Geosci., 1, 444-448, doi:10.1038/ngeo 218 .

Collins, J. A., et al. (2011), Interhemispheric symmetry of the tropical African rainbelt over the past 23,000 years, Nat. Geosci., 4, 42-45, doi:10.1038/ngeo1039.

deMenocal, P., et al. (2000), Abrupt onset and termination of the African Humid Period: rapid climate responses to gradual insolation forcing, Quat. Sci. Rev., 19, 347-361, doi:10.1016/S0277-3791(99)00081-5.

Denton, G. H., et al. (2005), The role of seasonality in abrupt climate change, Quat. Sci. Rev., 24, 1159-1182, doi:10.1016/j.quascirev.2004. 12.002 .

Giresse, P., et al. (1995), Quaternary sedimentary deposits on the Cameroon Shelf-Characterization of facies and late Quaternary shorelines, Quat. Int., 29-30, 75-82, doi:10.1016/1040-6182(95)00009-8.

Goldstein, S. L., R. K. O’Nions, and P. J. Hamilton (1984), A Sm-Nd isotopic study of atmospheric dusts and particulates from major river systems, Earth Planet. Sci. Lett., 70, 221-236, doi:10.1016/0012-821X (84)90007-4.

Grousset, F. E., and P. E. Biscaye (2005), Tracing dust sources and transport patterns using $\mathrm{Sr}, \mathrm{Nd}$ and $\mathrm{Pb}$ isotopes, Chem. Geol., 222(3-4), 149-167, doi:10.1016/j.chemgeo.2005.05.006.

Hanebuth, T. J. J., et al. (2009), Termination of the Last Glacial Maximum sea-level lowstand: The Sunda-Shelf data revisited, Global Planet. Change, 66, 76-84, doi:10.1016/j.gloplacha.2008.03.011.

Jacobsen, S. B., and G. J. Wasserburg (1980), Sm-Nd isotopic evolution of chondrites, Earth Planet. Sci. Lett., 50, 139-155, doi:10.1016/0012$821 \times(80) 90125-9$.

Kutzbach, J. E. (1981), Monsoon climate of the early Holocene: Climate experiment with Earth's orbital parameters for 9000 years ago, Science, 214, 59-61, doi:10.1126/science.214.4516.59.

Lézine, A.-M., and J.-P. Cazet (2005), High-resolution pollen record from core KW31, Gulf of Guinea, documents the history of the lowland forests of West Equatorial Africa since 40,000 yr ago, Quat. Res., 64(3), 432-443, doi:10.1016/j.yqres.2005.08.007.

Maley, J., and P. Brenac (1998), Vegetation dynamics, paleoenvironmental and climatic changes in the forest of western Cameroon during the last 28,000 years BP, Rev. Palaeobot. Palynol., 99, 157-187, doi:10.1016/ S0034-6667(97)00047-X.

Mulitza, S., M. Prange, J.-B. Stuut, M. Zabel, T. von Dobeneck, A. C Itambi, J. Nizou, M. Schulz, and G. Wefer (2008), Sahel megadroughts triggered by glacial slowdowns of Atlantic meridional overturning, Paleoceanography, 23, PA4206, doi:10.1029/2008PA001637.
Nicholson, S. E. (2009), A revised picture of the structure of the monsoon and land ITCZ over West Africa, Clim. Dyn., 32, 1155-1171, doi:10.1007/s00382-008-0514-3.

North Greenland Ice Core Project Members (2004), High-resolution record of Northern Hemisphere climate extending into the last interglacial period, Nature, 431, 147-151, doi:10.1038/nature02805.

Rea, D. K. (1994), The paleoclimatic record provided by the eolian deposition in the deep sea: The geologic history of wind, Rev. Geophys., 32, 159-195, doi:10.1029/93RG03257.

Sangen, M. (2011), New results on palaeoenvironmental conditions in equatorial Africa derived from alluvial sediments of Cameroonian rivers, Proc. Geol. Assoc., 122, 212-224.

Shanahan, T. M., et al. (2006), Paleoclimatic variations in West Africa from a record of late Pleistocene and Holocene lake level stands of Lake Bosumtwi, Ghana, Palaeogeogr. Palaeoclimatol. Palaeoecol., 242(3-4), 287-302, doi:10.1016/j.palaeo.2006.06.007.

Toteu, S. F., et al. (2001), New U-Pb and Sm-Nd data from north-central Cameroon and its bearing on the pre-Pan-African history of central Africa, Precambrian Res., 108, 45-73, doi:10.1016/S0301-9268(00)00149-2.

Weijers, J. W. H., et al. (2007), Coupled thermal and hydrological evolution of tropical Africa over the last deglaciation, Science, 315, 1701-1704, doi:10.1126/science. 1138131.

Weldeab, S., et al. (2005), Holocene African droughts relate to eastequatorial Atlantic cooling, Geology, 33, 981-984.doi:10.1130/G21874.1

Weldeab, S., et al. (2007a), 155,000 years of West African monsoon and ocean thermal evolution, Science, 316, 1303-1307, doi:10.1126/ science. 1140461

Weldeab, S., D. W. Lea, R. R. Schneider, and N. Andersen (2007b), Centennial scale climate instabilities in a wet early Holocene West African monsoon, Geophys. Res. Lett., 34, L24702.doi:10.1029/2007GL031898

M. Frank and T. Stichel, Leibniz-Institut für Meereswissenschaften an der Universität Kiel (IFM-GEOMAR), Wischhofstrasse 1-3, D-24148 Kiel, Germany.

B. Haley, College of Oceanic and Atmospheric Sciences, Oregon State University, 104 COAS Administration Bldg., Corvallis, OR 97331-5503, USA.

M. Sangen, Physische Geographie, Goethe Universität Frankfurt am Main, Altenhöfer Allee 1, D-60438 Frankfurt, Germany.

S. Weldeab, Department of Earth Science, University of California, Webb Hall, Santa Barbara, CA 93106-9630, USA. (weldeab@geol.ucsb. edu) 